Article

\title{
Neuroticism Predicts Subsequent Risk of Major Depression for Whites but Not Blacks
}

\author{
Shervin Assari 1,2 \\ 1 Department of Psychiatry, Medical School, University of Michigan, Ann Arbor, MI 48109, USA; \\ assari@umich.edu; Tel.: +1-734-232-0445; Fax: +1-734-615-8739 \\ 2 Center for Research on Ethnicity, Culture, and Health, School of Public Health, University of Michigan, \\ 1415 Washington Heights, 2858 SPH1, Ann Arbor, MI 48109-2029, USA
}

Received: 11 August 2017; Accepted: 4 September 2017; Published: 21 September 2017

\begin{abstract}
Cultural and ethnic differences in psychosocial and medical correlates of negative affect are well documented. This study aimed to compare blacks and whites for the predictive role of baseline neuroticism $(\mathrm{N})$ on subsequent risk of major depressive episodes (MDD) 25 years later. Data came from the Americans' Changing Lives (ACL) Study, 1986-2011. We used data on 1219 individuals (847 whites and 372 blacks) who had data on baseline N in 1986 and future MDD in 2011. The main predictor of interest was baseline N, measured using three items in 1986. The main outcome was 12 months MDD measured using the Composite International Diagnostic Interview (CIDI) at 2011. Covariates included baseline demographics (age and gender), socioeconomics (education and income), depressive symptoms [Center for Epidemiologic Studies Depression Scale (CES-D)], stress, health behaviors (smoking and driking), and physical health [chronic medical conditions, obesity, and self-rated health (SRH)] measured in 1986. Logistic regressions were used to test the predictive role of baseline $\mathrm{N}$ on subsequent risk of MDD 25 years later, net of covariates. The models were estimated in the pooled sample, as well as blacks and whites. In the pooled sample, baseline $\mathrm{N}$ predicted subsequent risk of MDD 25 years later $(\mathrm{OR}=2.23,95 \% \mathrm{CI}=1.14-4.34)$, net of covariates. We also found a marginally significant interaction between race and baseline $\mathrm{N}$ on subsequent risk of $\mathrm{MDD}(\mathrm{OR}=0.37,95 \% \mathrm{CI}=0.12-1.12)$, suggesting a stronger effect for whites compared to blacks. In race-specific models, among whites $(\mathrm{OR}=2.55 ; 95 \% \mathrm{CI}=1.22-5.32)$ but not blacks $(\mathrm{OR}=0.90$; $95 \% \mathrm{CI}=0.24-3.39)$, baseline $\mathrm{N}$ predicted subsequent risk of MDD. Black-white differences in socioeconomics and physical health could not explain the racial differences in the link between $\mathrm{N}$ and MDD. Blacks and whites differ in the salience of baseline $\mathrm{N}$ as a psychological determinant of MDD risk over a long period of time. This finding supports the cultural moderation hypothesis and is in line with other previously reported black-white differences in social, psychological, and medical correlates of negative affect and depression.
\end{abstract}

Keywords: ethnic groups; African Americans; whites; neuroticism; depression

\section{Background}

Neuroticism $(\mathrm{N})$ is a psychological trait with considerable public health significance [1]. $\mathrm{N}$ is a relatively stable personality trait that reflects individuals' tendency to respond to threats with negative emotions. Individuals with high $\mathrm{N}$ show intense and frequent emotional reactions to minor challenges in their lives [2]. Trait $\mathrm{N}$ also increases sensitivity to negative emotional information [3,4]. Therefore, individuals with high $\mathrm{N}$ frequently experience negative emotional arousal, which will increase their risk for a wide range of negatively charged emotions such as sadness, anger, anxiety, fear, worry, frustration, and loneliness [5-7].

The literature has documented a robust link between $\mathrm{N}$ and several undesirable physical and mental health outcomes such as anxiety, heart disease, stroke, hypertension, multi-morbidity, and 
mortality $[1,2,8-10]$. $\mathrm{N}$ also predicts health behaviors, health service use, and quality of life $[2,6]$. High $\mathrm{N}$ is also a vulnerability factor for frequency and severity of depression [11-15].

A recent study, however, suggests that $\mathrm{N}$ may not be universally harmful [9,16-19]. While $\mathrm{N}$ predicts a higher risk factor for cardiovascular mortality in women with low socioeconomic status (SES), it may be protective for women with high SES [9]. Park et al. found that $\mathrm{N}$ alters the link between social support and health in Japanese but not American individuals [20]. To explain the above findings, Kitayama has argued that $\mathrm{N}$ may be protective in some contexts, as it may reflect the sensitivity of people to potential costs associated with environmental exposures [20]. According to this argument, in some but not all contexts, high $\mathrm{N}$ means avoidance of exposure, which has positive health effects [21].

Although still new, a few studies have suggested that the health effects of $N$ [20] and other negative affective domains such as depression [22,23], anger [24,25], and hostility [24] depend on race, ethnicity, and culture. This is in line with the "differential effects hypothesis" [26], which suggests that social, psychosocial, and behavioral mechanisms that ultimately shape the health and illness of populations are not universal but population-specific. This hypothesis conceptualizes race as an effect modifier that alters the effect of the same risk factors on an outcome [27]. Considerable empirical support exists for this hypothesis, suggesting that group differences in the health effects of psychosocial constructs such as depression and negative affect are rules rather than exceptions [28,29].

While some evidence has suggested that context alters the health correlates of $N[9,20]$ and some research has shown that baseline $\mathrm{N}$ may have implications for subsequent mental health decades later [30], it is still unknown whether blacks and whites differ in the predictive role of high $\mathrm{N}$ on subsequent risk of depression years later. The aim of the current study was to compare blacks and whites for the predictive value of baseline $\mathrm{N}$ for subsequent risk of MDD 25 years later. To generate nationally representative results, we used data from a national sample of adults in the USA.

\section{Methods}

\subsection{Design and Setting}

Data came from the Americans' Changing Lives (ACL) study, 1986-2011. ACL is a longitudinal cohort study with a nationally representative sample. The detailed methodology of the ACL study is documented elsewhere in the literature [31,32].

\subsection{Ethical Considerations}

The University of Michigan Institutional Review Board approved the study protocol (HUM00051735). The study protocol was in accordance with The Code of Ethics of the World Medical Association (Declaration of Helsinki, Edinburgh 2000 revision). All participants provided informed written consent.

\subsection{Sampling and Participants}

The ACL cohort study has followed a nationally representative sample of American adults 25 years old and older from 1986 to 2011 . The ACL has applied a stratified multistage probability sampling of the U.S. population. The baseline population of ACL in 1986 included 3617 adults 25 years old and older who were non-institutionalized and were sampled from the continental USA. The study has oversampled blacks and older adults (age $>60$ ) at twice the rate of others.

\subsection{Analytical Sample}

The current study used whites and blacks who were in the study in wave 1 as well as wave 5 of the study (1986 and 2011). From the 3361 individuals (2205 whites and 1156 blacks) who were followed from 1986 for up to 25 years, 1219 individuals ( 847 whites and 372 blacks) had data on MDD in 2011 and entered our analysis. 


\subsection{Data Collection}

Baseline data on demographics (age, gender), socioeconomics, depressive symptoms, and health status were collected via face-to-face interviews in wave 1 in 1986. Baseline demographic factors (age and gender), socioeconomic status (education and income), depressive symptoms [Center for Epidemiologic Studies-Depression scale (CES-D)], stress, health behaviors (smoking and drinking), and physical health (Chronic Medical Conditions [CMC], obesity, and Self-Rated Health [SRH]) were potential confounders. The main predictor of interest was baseline N. The main outcome was clinical MDD 25 years later, measured by Composite International Diagnostic Interview (CIDI) in 2011.

\subsection{Measures}

Race and Ethnicity. The ACL study used multiple survey items in defining the race and ethnicity of the participants at baseline. First, participants were required to answer an open-ended question: "In addition to being American, what do you think of as your ethnic background or origins?" Then, a multiple-choice question was asked with the possibility that multiple categories could be chosen: "Are you white, black, American Indian, Asian, or another race?" Those who answered with more than one non-white group were required to say which one "best described" their race. The participants were also asked about their father's last name and the state or country in which the participant, participant's mother, and participant's father were born. Finally, the participants were required to answer whether they were of "Spanish or Hispanic descent, that is, Mexican, Mexican American, Chicano, Puerto Rican, Cuban, or Other Spanish?" Race categories were constructed based on the participants' responses to the above questions: "Non-Hispanic White", "Non-Hispanic Black", "Non-Hispanic Native American”, "Non-Hispanic Asian", and "Hispanic". We only included Non-Hispanic White and Non-Hispanic Black individuals in our analysis [22,23].

\subsubsection{Demographic Factors}

The ACL collected data on age (in years) and gender (considering male as the reference) at the first wave in 1986.

\subsubsection{Socio-Demographics (SES)}

The ACL collected baseline data on education (>12 years of schooling) and household income (a continuous variable).

\subsubsection{Health Behaviors}

Data were collected on smoking (i.e., tobacco use) and drinking (i.e., alcohol consumption) in 1986. Information was collected on self-reported history of smoking, using a dichotomous variable (current smoker $=1$, never or ex-smoker $=0$ ). Self-reported alcohol use was measured by asking whether or not the respondent currently drinks ( $1=$ current drinker; $0=$ non-drinker) [33]. Two dummy variables were created for smoking and drinking.

\subsubsection{Stressful Life Events (SLE)}

Data were collected data on the number of negative life events in the past three years. We used a measure that accords well with the current standards of measurement for major/traumatic events [34].

\subsubsection{Neuroticism $(\mathrm{N})$}

Neuroticism was measured with three indicators that asked respondents to indicate the extent to which they (1) consider themselves moody; (2) felt fed up; or (3) were tense or high-strung. The exact items read (1) Does your mood often go up and down? (2) Do you often feel fed up? (3) Would you call yourself tense or "high-strung"? Response categories for all items were "no," (1) "sometimes;" (3) and "yes;" (5) with a higher score on these indicators reflecting higher levels of neuroticism. 


\subsubsection{Depressive Symptoms}

The 11-item CES-D scale was used to measure depressive symptomatology: Participants were asked about depressed mood, feelings of guilt and worthlessness, feelings of helplessness and hopelessness, as well as restless sleep [10,15]. Each item was scored from 1 to 3 . We calculated a mean score ranging from 1 to 3 . Then we used a $\mathrm{Z}$ score that has a mean of 0 and a standard deviation of 1 . CES-D has high validity and reliability [35-38].

\subsubsection{Obesity}

Obesity was based on self-reported weights and heights. Weight and height were originally collected in pounds $(1$ pound $=0.453 \mathrm{~kg})$ and feet $(1 \mathrm{foot}=0.3048 \mathrm{~m}) /$ inches $(1$ inch $=0.0254 \mathrm{~m})$. Obesity was defined as a body mass index (BMI) of equal or larger than $30 \mathrm{~kg} / \mathrm{m}^{2}$. BMI based on self-reported data closely correlates with BMI based on direct height and weight measures [39].

\subsubsection{Chronic Medical Conditions (CMC)}

Number of CMC was collected using self-reported, physician-diagnosed medical conditions. Participants were asked if they have been informed by a healthcare provider about having one or more of seven focal conditions. The conditions listed were hypertension, diabetes, heart disease, stroke, cancer, chronic lung disease, and arthritis [32,40].

\subsubsection{Major Depressive Disorder (MDD)}

The main outcome was endorsement of DSM IV criteria for clinical diagnosis of MDD, measured using the Composite International Diagnostic Interview (CIDI). The CIDI—originally designed for the World Mental Health project-measures endorsement of criteria diagnosis of recent and lifetime non-psychotic mental disorders. The CIDI is administered by trained lay interviewers. CIDI and Structured Clinical Interviews for DSM-IV diagnoses (SCID) have shown good concordance for diagnosis of major depressive disorders, as reflected by the area under the receiver operating characteristic curve (AUC) [41-44].

\subsection{Statistical Analysis}

Stata 13.0 (Stata Corp., College Station, TX, USA) was used for data analysis. Stata enabled us to account for the complex sample design of the ACL study by considering sampling and non-response weights. Taylor series linearization was used to estimate standard errors (SE). Subpopulation survey commands were used for data analysis. The $p$-value significance cut-off point was considered 0.05 and 0.1 for main effect and interactions, respectively.

Descriptive and frequency tables were used for univariate analysis. Four survey logistic regression models were used for multivariable analysis. In all logistic regression models, baseline $\mathrm{N}$ was the main independent variable, subsequent MDD in 2011 was the main outcome, and demographics, SES, depressive symptoms, stress, health behaviors, and physical health were covariates. First we ran two models in the pooled sample. In Model 1, we only tested the main effect of $\mathrm{N}$ and covariates. In Model 2, we also included the $\mathrm{N}$ by race interaction. Then we conducted the same models specific to whites (Model 3) and blacks (Model 4). Odds Ratio and standard errors, 95\% CI, and p values were reported for each variable.

\section{Results}

\subsection{Descriptive Statistics}

Table 1 presents descriptive statistics in the pooled sample, and based on race. Independent samples' $t$-test and chi-squared test showed lower education, income, and drinking but higher N, SLE, depressive symptoms, $\mathrm{CMC}$, obesity, and smoking among blacks compared to whites. 
Table 1. Descriptive statistics for baseline characteristics based on race.

\begin{tabular}{|c|c|c|c|c|c|c|}
\hline & \multicolumn{2}{|c|}{ All $(n=1219)$} & \multicolumn{2}{|c|}{ Whites $(n=847)$} & \multicolumn{2}{|c|}{ Blacks $(n=372)$} \\
\hline & $n$ (SE) & $95 \%$ CI & $n$ (SE) & $95 \% \mathrm{CI}$ & $n$ (SE) & $95 \%$ CI \\
\hline \multicolumn{7}{|l|}{ Race * } \\
\hline White & $90.06(0.01)$ & $87.86-91.90$ & - & - & - & - \\
\hline Black & $9.94(0.01)$ & $8.10-12.14$ & - & - & - & - \\
\hline \multicolumn{7}{|l|}{ Gender* } \\
\hline Men & $46.11(0.02)$ & $42.81-49.45$ & $46.57(0.02)$ & $42.98-50.19$ & $41.97(0.03)$ & $35.78-48.43$ \\
\hline Women & $53.89(0.02)$ & $50.55-57.19$ & $53.43(0.02)$ & $49.81-57.02$ & $58.03(0.03)$ & $51.57-64.22$ \\
\hline \multicolumn{7}{|l|}{ Obese * } \\
\hline No & $86.78(0.01)$ & $84.70-88.61$ & $87.23(0.01)$ & $84.82-89.30$ & $82.69(0.02)$ & $77.64-86.79$ \\
\hline Yes & $13.22(0.01)$ & $11.39-15.30$ & $12.77(0.01)$ & $10.70-15.18$ & $17.31(0.02)$ & $13.21-22.36$ \\
\hline \multicolumn{7}{|c|}{ Any chronic medical conditions * } \\
\hline No & $68.86(0.02)$ & $65.25-72.24$ & $69.92(0.02)$ & $65.94-73.62$ & $59.22(0.03)$ & $52.30-65.79$ \\
\hline Yes & $31.14(0.02)$ & 27.7634.75- & $30.08(0.02)$ & $26.38-34.06$ & $40.78(0.03)$ & $34.21-47.70$ \\
\hline \multicolumn{7}{|l|}{ Drinking * } \\
\hline No & $32.66(0.02)$ & $28.72-36.86$ & $31.31(0.02)$ & $27.19-35.76$ & $44.84(0.04)$ & $37.66-52.24$ \\
\hline Yes & $67.34(0.02)$ & $63.14-71.28$ & $68.69(0.02)$ & $64.24-72.81$ & $55.16(0.04)$ & $47.76-62.34$ \\
\hline \multicolumn{7}{|l|}{ Smoking * } \\
\hline No & $70.65(0.02)$ & $66.93-74.11$ & $71.43(0.02)$ & $67.36-75.18$ & $63.55(0.03)$ & $56.37-70.17$ \\
\hline \multirow{2}{*}{\multicolumn{7}{|c|}{$\begin{array}{l}\text { Yes } \\
\text { MDD * }\end{array}$}} \\
\hline & & & & & & \\
\hline No & $91.23(0.01)$ & $89.13-92.96$ & $91.51(0.01)$ & 89.27-93.31 & $88.76(0.02)$ & $83.95-92.26$ \\
\hline Yes & $8.77(0.01)$ & $7.04-10.87$ & $8.49(0.01)$ & $6.69-10.73$ & $11.24(0.02)$ & $7.74-16.05$ \\
\hline \multicolumn{7}{|l|}{ Neuroticism * } \\
\hline Low & $83.52(0.01)$ & $80.43-86.20$ & $83.98(0.02)$ & $80.41-87.01$ & $79.29(0.02)$ & $74.64-83.27$ \\
\hline \multirow[t]{2}{*}{ High } & $16.48(0.01)$ & $13.80-19.57$ & $16.02(0.02)$ & $12.99-19.59$ & $20.71(0.02)$ & $16.73-25.36$ \\
\hline & $\%$ (SE) & $95 \%$ CI & $\%$ (SE) & $95 \%$ CI & $\%$ (SE) & $95 \%$ CI \\
\hline Age & $47.77(0.53)$ & $46.69-48.84$ & $47.96(0.60)$ & $46.75-49.17$ & $46.33(0.72)$ & $44.89-47.78$ \\
\hline Education $(>12$ years) * & $12.53(0.10)$ & $12.34-12.73$ & $12.69(0.11)$ & $12.48-12.90$ & $11.37(0.23)$ & $10.90-11.84$ \\
\hline Household income* & $5.41(0.09)$ & $5.22-5.60$ & $5.57(0.10)$ & $5.36-5.77$ & $4.25(0.18)$ & $3.88-4.62$ \\
\hline Stress * & $0.88(0.02)$ & $0.84-0.92$ & $0.88(0.02)$ & $0.84-0.92$ & $0.87(0.03)$ & $0.81-0.94$ \\
\hline Depressive symptoms * & $-0.03(0.02)$ & $-0.08-0.02$ & $-0.07(0.03)$ & $-0.13-0.02$ & $0.28(0.05)$ & $0.18-0.38$ \\
\hline Neuroticism * & $-0.01(0.03)$ & $-0.06-0.04$ & $-0.01(0.03)$ & $-0.07-0.05$ & $0.01(0.04)$ & $-0.07-0.09$ \\
\hline
\end{tabular}

\subsection{Models in the Pooled Sample}

Table 2 summarizes the results of two logistic regression models on the association between baseline $\mathrm{N}$ and subsequent risk of CIDI-based MDD 25 years later in the pooled sample, net of baseline controls. Based on Model 1, in the pooled sample, higher $\mathrm{N}$ at baseline $(\mathrm{OR}=2.23,95 \% \mathrm{CI}=1.14-4.34)$ was positively associated with risk of CIDI-based MDD 25 years later in 2011. Based on Model 2, in the pooled sample, $\mathrm{N}$ at baseline symptoms showed a marginally significant interaction with race $(\mathrm{OR}=0.37,95 \% \mathrm{CI}=0.12-1.12)$, suggesting a stronger effect of baseline $\mathrm{N}$ on subsequent MDD 25 years later for whites compared to blacks. Such interaction was the net of socioeconomic and health in 1986 (Table 2). 
Table 2. Summary of logistic regression models on the association baseline neuroticism and CIDI-based major depressive episode 25 years later based on race $(n=1219)$.

\begin{tabular}{ccccccc}
\hline & OR (SE) & 95\% CI & $p$ & OR & $p$ \\
\cline { 2 - 6 } & & Model 1 & & Model 2 & \\
\hline Race(Blacks) & $0.88(0.22)$ & $0.54-1.45$ & 0.612 & $1.23(0.34)$ & $0.70-2.16$ & 0.455 \\
Age & $0.99(0.01)$ & $0.96-1.02$ & 0.342 & $0.99(0.01)$ & $0.96-1.02$ & 0.325 \\
Gender (Women) & $1.02(0.25)$ & $0.63-1.66$ & 0.927 & $1.03(0.25)$ & $0.63-1.69$ & 0.894 \\
Education (>12 years) & $0.99(0.08)$ & $0.85-1.17$ & 0.941 & $1.00(0.08)$ & $0.85-1.17$ & 0.964 \\
Household income & $0.98(0.06)$ & $0.86-1.12$ & 0.778 & $0.98(0.06)$ & $0.86-1.11$ & 0.751 \\
Any chronic medical condition & $1.18(0.31)$ & $0.70-1.99$ & 0.530 & $1.20(0.31)$ & $0.71-2.03$ & 0.477 \\
Obese & $1.42(0.39)$ & $0.81-2.48$ & 0.215 & $1.41(0.39)$ & $0.81-2.45$ & 0.219 \\
Drinking & $0.73(0.16)$ & $0.47-1.12$ & 0.148 & $0.73(0.16)$ & $0.48-1.13$ & 0.156 \\
Smoking & $1.55(0.44)$ & $0.87-2.75$ & 0.130 & $1.53(0.44)$ & $0.86-2.73$ & 0.141 \\
Stress & $1.36(0.21)$ & $0.99-1.86$ & 0.054 & $1.36(0.21)$ & $1.00-1.85$ & 0.050 \\
Depressive symptoms & $1.55(0.18)$ & $1.22-1.97$ & 0.001 & $1.56(0.18)$ & $1.23-1.98$ & 0.000 \\
Neuroticism & $2.23(0.74)$ & $1.14-4.34$ & 0.020 & $2.51(0.88)$ & $1.24-5.08$ & 0.012 \\
Neuroticism $\times$ Race & - & - & - & $0.37(0.20)$ & $0.12-1.12$ & 0.077 \\
Constant & $0.10(0.13)$ & $0.01-1.49$ & 0.092 & $0.09(0.12)$ & $0.01-1.41$ & 0.085 \\
\hline
\end{tabular}

Notes: CIDI: Composite International Diagnostic Interview.

\subsection{Models among Whites and Blacks}

According to Model 3, higher level of $\mathrm{N}$ at baseline was a significant predictor of MDD 25 years later in 2011 in whites $(\mathrm{OR}=2.55,95 \% \mathrm{CI}=1.22-5.32)$. According to Model 4, higher $\mathrm{N}(\mathrm{OR}=0.90$, $95 \% \mathrm{CI}=0.24-3.39$ ) was not predictive of MDD 25 years later in 2011 for blacks (Table 3 ).

Table 3. Summary of logistic regression models on the association baseline neuroticism and CIDI-based major depressive episode 25 years later based on race $(n=1219)$.

\begin{tabular}{ccccccc}
\hline & OR (SE) & 95\% CI & $p$ & OR (SE) & 95\% CI & $p$ \\
\cline { 2 - 7 } & \multicolumn{3}{c}{ Model 3 } & \multicolumn{3}{c}{ Model 4 } \\
\cline { 2 - 7 } & \multicolumn{3}{c}{ Whites $(\boldsymbol{n}=\mathbf{8 4 7})$} \\
Age & $0.98(0.02)$ & $0.95-1.02$ & 0.343 & $0.98(0.03)$ & $0.93-1.03$ & 0.374 \\
Gender (Women) & $1.05(0.30)$ & $0.59-1.85$ & 0.863 & $0.95(0.59)$ & $0.27-3.34$ & 0.932 \\
Education (>12 years) & $1.01(0.10)$ & $0.83-1.22$ & 0.929 & $0.91(0.12)$ & $0.71-1.18$ & 0.467 \\
Household income & $0.97(0.07)$ & $0.84-1.13$ & 0.685 & $1.06(0.09)$ & $0.89-1.26$ & 0.524 \\
Any chronic medical condition & $1.31(0.40)$ & $0.71-2.42$ & 0.376 & $0.63(0.31)$ & $0.23-1.68$ & 0.347 \\
Obese & $1.33(0.46)$ & $0.66-2.69$ & 0.421 & $2.07(0.94)$ & $0.82-5.20$ & 0.118 \\
Drinking & $0.65(0.15)$ & $0.40-1.05$ & 0.075 & $1.52(0.83)$ & $0.50-4.61$ & 0.450 \\
Smoking & $1.42(0.44)$ & $0.76-2.63$ & 0.267 & $2.13(0.72)$ & $1.08-4.23$ & 0.031 \\
Stress & $1.38(0.25)$ & $0.96-2.00$ & 0.084 & $1.32(0.20)$ & $0.97-1.79$ & 0.073 \\
Depressive symptoms & $1.53(0.20)$ & $1.18-1.99$ & 0.002 & $1.83(0.35)$ & $1.25-2.70$ & 0.003 \\
Neuroticism & $2.55(0.93)$ & $1.22-5.32$ & 0.014 & $0.90(0.59)$ & $0.24-3.39$ & 0.871 \\
Constant & $0.09(0.13)$ & $0.00-1.87$ & 0.116 & $0.24(0.64)$ & $0.00-54.25$ & 0.596 \\
\hline
\end{tabular}

\section{Discussion}

We found that high $\mathrm{N}$ at baseline better predicted subsequent risk of clinical MDD 25 years later in whites compared to blacks. In race-specific models, baseline N predicted MDD for whites but not blacks.

Previous research has suggested that negative affect in general $[22,23,25]$ and $N$ in particular $[9,20]$ may have group-specific rather than universal health effects. Assari has shown that depressive symptoms predict all-cause [22] and cause-specific [23] mortality in whites but not blacks. Race has been shown to interact with baseline depressive symptoms on risk of all cause and cause-specific mortality, suggesting a stronger effect of baseline depressive symptoms on mortality for whites compared to blacks [22,23]. Hostility and anger have also predicted cardiovascular mortality in whites but not blacks [24]. Park et al. found that $\mathrm{N}$ alters the link between social support and health in Japanese but not American individuals [20], and anger may even be linked to better health in some 
cultures [25]. Park et al. showed that for white Americans, lower social standing was associated with greater expression of anger, while for Japanese individuals high social status was associated with more anger expression. While for white Americans, anger expression was predicted by subjective social status, for Japanese individuals the objective social status predicted anger expression [45].

To explain the mixed findings on the health effects of N, Kitayama et al. have argued that $\mathrm{N}$ may be protective in some contexts, as it may reflect the sensitivity of people to potential costs associated with environmental exposures [20]. Thus, at least in some contexts, individuals with high $\mathrm{N}$ may be able to avoid exposure, which may have positive health effects [21]. Jackson has attributed the differential effects of stress and chronic disease on depression of blacks and whites to differential behavioral coping mechanisms that populations use [46-49]. Assari has, however, shown that the moderating effects of contextual factors such as race, ethnicity, and culture hold for a wide range of psychosocial domains and health outcomes $[22,23,28,29,50-56]$.

Some of these findings may be, at least in part, due to the effects of culture in shaping emotions [57-59]. Based on the behavioral adjustment model, Kitayama et al. proposed that, if combined with one's flexibility to change behavior in face of need, $\mathrm{N}$ can alert individuals to potential threats in the environment and, as a consequence, can represent lower levels of exposure to interpersonal and environmental threats $[60,61]$. It is, however, still unknown by which exact mechanism race, ethnicity, gender, and culture alter the health outcomes associated with psychosocial factors such as $\mathrm{N}$ and depression.

A wide range of subjective measures of mental health have shown stronger links with objective measures of physical and mental health in whites than blacks [50,56,62,63]. Race may also alter how traits that reflect personality or distress covary with particular psychiatric disorders such as MDD based on structural interviews [62]. Perceived mental health better reflects psychiatric disorders among whites than in minorities such as blacks [56]. Concordance between CES-D score and clinical depression also depends on contextual factors such as ethnicity, culture, and social class [10,64]. Similar findings have been reported on the SLE-MDD link $[65,66]$.

In the pooled sample, we could find a significant interaction between race and baseline $\mathrm{N}$ on subsequent MDD risk, suggesting that the predictive role of baseline $\mathrm{N}$ for MDD is larger for whites compared to blacks. Such black-white difference was not due to racial differences in socioeconomic and health status. Our race-specific models also showed that baseline $\mathrm{N}$ is predictive of subsequent risk of MDD among whites but not blacks, net of SES and health status at baseline. These findings are in line with previous findings on the differential role of CES-D on subsequent risk of MDD [10] as well as the black-white differences in social, psychological, and medical correlates of negative affect, MDD, and depressive symptoms [40,52-55,65-67].

Based on our findings, compared to whites, blacks had higher $\mathrm{N}$ in 1986 and lower risk of endorsement of CIDI-based MDD 25 years later in 2011. The literature has documented systematically weaker effects of a wide range of psychosocial factors on health outcomes for blacks compared to whites [50-54]. We cannot rule out that at least some of the findings may be due to measurement issues regarding diagnosis of clinical depression among blacks $[68,69]$. There is some previous research suggesting that CIDI validity may differ for blacks and whites [70-72], which may in turn result in differential correlates of depression based on race. Finally, it is not clear whether racial groups are similar in terms of the stability of personality traits such as $\mathrm{N}$ over time [72].

There are a number of limitations to our study. First, we used a three-item measure for N, which may have differential validity across racial groups. As a result, there is a need for replication of these findings using standardized measures of N. Secondly, in our analysis we conceptualized N, SES, stress, depressive symptoms, and physical health as fixed factors; however, all these constructs are subject to change over a long period of time. Third, the sample size was not balanced between whites and blacks, and the low sample size of blacks may have caused statistically under-powered study for blacks. Fourth, we did not control for diagnosis of MDD, mental health care use, or anti-depressant prescription in this study. Fifth, the 25-year follow-up period may have caused selective attrition in 
this study. Due to the higher mortality of blacks, race was not independent of attrition in this study. Future research may consider replication of the current findings using shorter follow-up periods. Despite these limitations, this is one of the first studies on black-white differences in the predictive role of baseline $\mathrm{N}$ on subsequent risk of MDD diagnosis based on CIDI 25 years later in a nationally representative sample of American adults.

In conclusion, baseline $\mathrm{N}$ predicts subsequent risk of MDD in whites but not blacks. Racial differences in the effect of baseline $\mathrm{N}$ on subsequent risk of CIDI-based MDD are in line with previous findings on the cultural moderation of correlates of negative affect ( $\mathrm{N}$, hostility, anger, depression, depressive symptoms), as well as racial differences in the complex links between socioeconomic status, negative affect, and physical health [73]. Future neuroscience research is needed to compare biological and social correlates of high $\mathrm{N}$ across racial groups.

Acknowledgments: Shervin Assari is supported by the Heinz C. Prechter Bipolar Research Fund and the Richard Tam Foundation at the University of Michigan Depression Center. The Americans' Changing Lives (ACL) study was supported by Grant \#AG018418 from the National Institute on Aging (DHHS/NIH), and per the NIH Public Access Policy requires that peer-reviewed research publications generated with NIH support are made available to the public through PubMed Central. NIH is not responsible for the data collection or analyses represented in this article. The ACL study was conducted by the Institute of Social Research, University of Michigan.

Conflicts of Interest: The author declares no conflicts of interest.

\section{References}

1. Lahey, B.B. Public health significance of neuroticism. Am. Psychol. 2009, 64, 241-256. [CrossRef] [PubMed]

2. Mroczek, D.K.; Spiro, A.; Turiano, N. Do health behaviors explain the effect of neuroticism on mortality? Longitudinal findings from the va normative aging study. J. Res. Personal. 2009, 43, 653-659. [CrossRef] [PubMed]

3. Derryberry, D.; Reed, M.A. Temperament and attention: Orienting toward and away from positive and negative signals. J. Personal. Soc. Psychol. 1994, 66, 1128-1139. [CrossRef]

4. Wilson, E.J.; MacLeod, C.; Mathews, A.; Rutherford, E.M. The causal role of interpretive bias in anxiety reactivity. J. Abnorm. Psychol. 2006, 115, 103-111. [CrossRef] [PubMed]

5. Costa, P.T.; McCrae, R.R. The SAGE Handbook of Personality Theory and Assessment; Boyles, G., Matthews, G., Saklofske, D., Eds.; Sage: New Delhi, India, 2008; pp. 179-199.

6. Costa, P.T.; McCrae, R.R. Influence of extraversion and neuroticism on subjective well-being: Happy and unhappy people. J. Personal. Soc. Psychol. 1980, 38, 668-678. [CrossRef]

7. Rusting, C.L.; Larsen, R.J. Extraversion, neuroticism, and susceptibility to positive and negative affect: A test of two theoretical models. Personal. Individ. Differ. 1997, 22, 607-612. [CrossRef]

8. Shipley, B.A.; Weiss, A.; Der, G.; Taylor, M.D.; Deary, I.J. Neuroticism, extraversion, and mortality in the UK Health and Lifestyle Survey: A 21-year prospective cohort study. Psychosom. Med. 2007, 69, 923-931. [CrossRef] [PubMed]

9. Hagger-Johnson, G.; Roberts, B.; Boniface, D.; Sabia, S.; Batty, G.D.; Elbaz, A.; Singh-Manoux, A.; Deary, I.J. Neuroticism and cardiovascular disease mortality: Socioeconomic status modifies the risk in women (UK Health and Lifestyle Survey). Psychosom. Med. 2012, 74, 596-603. [CrossRef] [PubMed]

10. Moazen-Zadeh, E.; Assari, S. Depressive Symptoms Predict Major Depressive Disorder after 15 Years among Whites but Not Blacks. Front. Public Health 2016, 4, 13. [CrossRef] [PubMed]

11. Barnhofer, T.; Chittka, T. Cognitive reactivity mediates the relationship between neuroticism and depression. Behav. Res. Ther. 2010, 48, 275-281. [CrossRef] [PubMed]

12. Farmer, A.; Redman, K.; Harris, T.; Mahmood, A.; Sadler, S.; Pickering, A.; McGuffin, P. Neuroticism, extraversion, life events and depression. The Cardiff Depression Study. Br. J. Psychiatry 2002, 181, 118-122. [PubMed]

13. Roelofs, J.; Huibers, M.; Peeters, F.; Arntz, A.; van Os, J. Rumination and worrying as possible mediators in the relation between neuroticism and symptoms of depression and anxiety in clinically depressed individuals. Behav. Res. Ther. 2008, 46, 1283-1289. [CrossRef] [PubMed] 
14. Lam, D.; Smith, N.; Checkley, S.; Rijsdijk, F.; Sham, P. Effect of neuroticism, response style and information processing on depression severity in a clinically depressed sample. Psychol. Med. 2003, 33, 3469-3479. [CrossRef]

15. Sen, S.; Nesse, R.M.; Stoltenberg, S.F.; Li, S.; Gleiberman, L.; Chakravarti, A.; Weder, A.B.; Burmeister, M. A BDNF coding variant is associated with the NEO personality inventory domain neuroticism, a risk factor for depression. Neuropsychopharmacology 2003, 28, 397-401. [CrossRef] [PubMed]

16. Nesse, R.M.; Ellsworth, P.C. Evolution, emotions, and emotional disorders. Am. Psychol. 2009, 64, 129-139. [CrossRef] [PubMed]

17. Marks, I.M.; Nesse, R.M. Fear and fitness: An evolutionary analysis of anxiety disorders. Ethol. Sociobiol. 1994, 15, 247-261. [CrossRef]

18. Friedman, H.S. Long-Term Relations of Personality and Health: Dynamisms, Mechanisms, Tropisms. J. Personal. 2000, 68, 1089-1107. [CrossRef]

19. Turiano, N.A.; Mroczek, D.K.; Moynihan, J.; Chapman, B.P. Big 5 personality traits and interleukin-6: Evidence for "healthy Neuroticism" in a US population sample. Brain Behav. Immun. 2013, 28, 83-89. [CrossRef] [PubMed]

20. Park, J.; Kitayama, S.; Karasawa, M.; Curhan, K.; Markus, H.R.; Kawakami, N.; Miyamoto, Y.; Love, G.D.; Coe, C.L.; Ryff, C.D. Clarifying the links between social support and health: Culture, stress, and neuroticism matter. J. Health Psychol. 2013, 18, 226-235. [CrossRef] [PubMed]

21. Karney, B.; Bradbury, T. The longitudinal course of marital quality and stability: A review of theory, method, and research. Psychol. Bull. 1995, 118, 3-34. [CrossRef] [PubMed]

22. Assari, S.; Moazen-Zadeh, E.; Lankarani, M.M.; Micol-Foster, V. Race, Depressive Symptoms, and All-Cause Mortality in the United States. Front. Public Health 2016, 4, 40. [CrossRef] [PubMed]

23. Assari, S.; Burgard, S. Black-White differences in the effect of baseline depressive symptoms on deaths due to renal diseases: 25 years follow up of a nationally representative community sample. J. Ren. Inj. Prev. 2015, 4, 127-134. [CrossRef] [PubMed]

24. Assari, S. Hostility, Anger, and Cardiovascular Mortality among Blacks and Whites. Res. Cardiovasc. Med. 2016. [CrossRef]

25. Kitayama, S.; Park, J.; Boylan, J.M.; Miyamoto, Y.; Levine, C.S.; Markus, H.R.; Karasawa, M.; Coe, C.L.; Kawakami, N.; Love, G.D.; et al. Expression of anger and ill health in two cultures: An examination of inflammation and cardiovascular risk. Psychol. Sci. 2015, 26, 211-220. [CrossRef] [PubMed]

26. Assari, S. Race and ethnic differences in additive and multiplicative effects of depression and anxiety on cardiovascular risk. Int. J. Prev. Med. 2016, 7, 22. [CrossRef] [PubMed]

27. Assari, S.; Lankarani, M.M. Education and Alcohol Consumption among Older Americans; Black-White Differences. Front. Public Health 2016, 4, 67. [CrossRef] [PubMed]

28. Assari, S.; Lankarani, M.M.; Burgard, S. Black-white difference in long-term predictive power of self-rated health on all-cause mortality in United States. Ann. Epidemiol. 2016, 26, 106-114. [CrossRef] [PubMed]

29. Assari, S.; Lankarani, M.M. Race and Urbanity Alter the Protective Effect of Education but not Income on Mortality. Front. Public Health 2016, 4, 100. [CrossRef] [PubMed]

30. Gale, C.R.; Booth, T.; Mõttus, R.; Kuh, D.; Deary, I.J. Neuroticism and Extraversion in Youth Predict Mental Wellbeing and Life Satisfaction 40 Years Later. J. Res. Personal. 2013, 47, 687-697. [CrossRef] [PubMed]

31. House, J.S. Americans' Changing Lives: Waves I, II, III, IV, and V, 1986, 1989, 1994, 2002, and 2011. ICPSR04690-v7; Inter-university Consortium for Political and Social Research [Distributor]: Ann Arbor, MI, USA, 2014.

32. House, J.S.; Kessler, R.C.; Herzog, A.R. Age, socioeconomic status, and health. Milbank Q. 1990, 68, $383-411$. [CrossRef] [PubMed]

33. Harvey, I.S.; Alexander, K. Perceived social support and preventive health behavioral outcomes among older women. J. Cross Cult. Gerontol. 2012, 27, 275-290. [CrossRef] [PubMed]

34. Lantz, P.M.; House, J.S.; Mero, R.P.; Williams, D.R. Stress, life events, and socioeconomic disparities in health: Results from the Americans' Changing Lives Study. J. Health Soc. Behav. 2005, 46, 274-288. [CrossRef] [PubMed]

35. Amtmann, D.; Kim, J.; Chung, H.; Bamer, A.M.; Askew, R.L.; Wu, S.; Cook, K.F.; Johnson, K.L. Comparing CESD-10, PHQ-9, and PROMIS depression instruments in individuals with multiple sclerosis. Rehabil. Psychol. 2014, 59, 220. [CrossRef] [PubMed] 
36. Zhang, W.; O’Brien, N.; Forrest, J.I.; Salters, K.A.; Patterson, T.L.; Montaner, J.; Hogg, R.S.; Lima, V.D. Validating a shortened depression scale (10 item CES-D) among HIV-positive people in British Columbia, Canada. PLoS ONE 2012, 7, e40793. [CrossRef] [PubMed]

37. Andresen, E.M.; Malmgren, J.A.; Carter, W.B.; Patrick, D.L. Screening for depression in well older adults: Evaluation of a short form of the CES-D. Am. J. Prev. Med. 1994, 10, 77-84. [PubMed]

38. Roberts, R.E. Reliability of the CES-D scale in different ethnic contexts. Psychiatry Res. 1980, 2, 125-134. [CrossRef]

39. Gavin, A.R.; Rue, T.; Takeuchi, D. Racial/ethnic differences in the association between obesity and major depressive disorder: Findings from the Comprehensive Psychiatric Epidemiology Surveys. Public Health Rep. 2010, 125, 698-708. [CrossRef] [PubMed]

40. Assari, S.; Burgard, S.; Zivin, K. Long-Term Reciprocal Associations between Depressive Symptoms and Number of Chronic Medical Conditions: Longitudinal Support for Black-White Health Paradox. J. Racial Ethn. Health Disparit. 2015, 2, 589-597. [CrossRef] [PubMed]

41. Robins, L.N.; Wing, J.; Wittchen, H.U.; Helzer, J.E.; Babor, T.F.; Burke, J.; Farmer, A.; Jablenski, A.; Pickens, R.; Regier, D.A. The Composite International Diagnostic Interview: An epidemiologic instrument suitable for use in conjunction with different diagnostic systems and in different cultures. Arch. Gen. Psychiatry 1988, 45, 1069-1077. [CrossRef] [PubMed]

42. Wittchen, H.U. Reliability and validity studies of the WHO-Composite International Diagnostic Interview (CIDI): A critical review. J. Psychiatry Res. 1994, 28, 57-84. [CrossRef]

43. Kessler, R.C.; Wittchen, H.U.; Abelson, J.M.; McGonagle, K.; Schwarz, N.; Kendler, K.S.; Knäuper, B.; Zhao, S. Methodological studies of the Composite International Diagnostic Interview (CIDI) in the US national comorbidity survey (NCS). Int. J. Methods Psychiatr. Res. 1998, 7, 33-55. [CrossRef]

44. Kessler, R.C.; Calabrese, J.R.; Farley, P.A.; Gruber, M.J.; Jewell, M.A.; Katon, W.; Kect, P.E.; Nierenberg, A.A.; Sampson, N.A.; Shear, M.K.; et al. Composite International Diagnostic Interview screening scales for DSM-IV anxiety and mood disorders. Psychol. Med. 2013, 43, 1625-1637. [CrossRef] [PubMed]

45. Park, J.; Kitayama, S.; Markus, H.R.; Coe, C.L.; Miyamoto, Y.; Karasawa, M.; Curhan, K.B.; Love, G.D.; Kawakami, N.; Boylan, J.M.; et al. Social status and anger expression: The cultural moderation hypothesis. Emotion 2013, 13, 1122-1131. [CrossRef] [PubMed]

46. Jackson, J.S.; Knight, K.M.; Rafferty, J.A. Race and unhealthy behaviors: Chronic stress, the HPA axis, and physical and mental health disparities over the life course. Am. J. Public Health 2010, 100, 933-999. [CrossRef] [PubMed]

47. Jackson, J.S.; Knight, K.M. Race and self-regulatory health behaviors: The role of the stress response and the HPA axis in physical and mental health disparities. In Social Structures, Aging, and Self-Regulation in the Elderly; Schaie, K.W., Carstensen, L.L., Eds.; Springer: New York, NY, USA, 2006; pp. 189-207.

48. Mezuk, B.; Abdou, C.M.; Hudson, D.; Kershaw, K.N.; Rafferty, J.A.; Lee, H.; Jackson, J.S. “White Box" Epidemiology and the Social Neuroscience of Health Behaviors: The Environmental Affordances Model. Soc. Ment. Health 2013, 3. [CrossRef] [PubMed]

49. Mezuk, B.; Rafferty, J.A.; Kershaw, K.N.; Hudson, D.; Abdou, C.M.; Lee, H.; Eaton, W.W.; Jackson, J.S. Reconsidering the role of social disadvantage in physical and mental health: Stressful life events, health behaviors, race, and depression. Am. J. Epidemiol. 2010, 172, 1238-1249. [CrossRef] [PubMed]

50. Jang, Y.; Park, N.S.; Kang, S.-Y.; Chiriboga, D.A. Racial/ethnic differences in the association between symptoms of depression and self-rated mental health among older adults. Community Ment. Health J. 2014, 50, 325-330. [CrossRef] [PubMed]

51. Canady, R.B.; Stommel, M.; Holzman, C. Measurement properties of the Centers for Epidemiological Studies Depression Scale (CES-D) in a sample of African-American and non-Hispanic White pregnant women. J. Nurs. Meas. 2009, 17, 91. [CrossRef] [PubMed]

52. Assari, S. Ethnic Groups Differ in How Poor Self-Rated Mental Health Reflects Psychiatric Disorders. J. Racial Ethn. Health Disparit. 2017. [CrossRef] [PubMed]

53. Assari, S.; Sonnega, A.; Leggett, A.; Pepin, R.L. Residual Effects of Restless Sleep over Depressive Symptoms on Chronic Medical Conditions: Race by Gender Differences. J. Racial Ethn. Health Disparit. 2016. [CrossRef] [PubMed] 
54. Watkins, D.C.; Assari, S.; Johnson-Lawrence, V. Race and ethnic group differences in comorbid major depressive disorder, generalized anxiety disorder, and chronic medical conditions. J. Racial Ethn. Health Disparit. 2015, 2, 385-394. [CrossRef] [PubMed]

55. Assari, S.; Caldwell, C.H. Gender and ethnic differences in the association between obesity and depression among black adolescents. J. Racial Ethn. Health Disparit. 2015, 2, 481-493. [CrossRef] [PubMed]

56. Kim, G.; DeCoster, J.; Chiriboga, D.A.; Jang, Y.; Allen, R.S.; Parmelee, P. Associations between self-rated mental health and psychiatric disorders among older adults: Do racial/ethnic differences exist? Am. J. Geriatr. Psychiatry 2011, 19, 416-422. [CrossRef] [PubMed]

57. Mesquita, B. Emotions in collectivist and individualist contexts. J. Personal. Soc. Psychol. 2001, 80, 68-74. [CrossRef]

58. Imada, T.; Ellsworth, P.C. Proud Americans and lucky Japanese: Cultural differences in appraisal and corresponding emotion. Emotion 2011, 11, 329-345. [CrossRef] [PubMed]

59. Mesquita, B.; Frijda, N.H. Cultural variations in emotions: A review. Psychol. Bull. 1992, 112, $179-204$. [CrossRef] [PubMed]

60. Kan, C.; Kawakami, N.; Karasawa, M.; Love, G.D.; Coe, C.L.; Miyamoto, Y.; Ryff, C.D.; Kitayama, S.; Curhan, K.B.; Markus, H.R. Psychological resources as mediators of the association between social class and health: Comparative findings from Japan and the USA. Int. J. Behav. Med. 2014, 21, 53-65. [CrossRef] [PubMed]

61. Assari, S.; Dejman, M.; Neighbors, H.W. Ethnic differences in separate and additive effects of anxiety and depression on self-rated mental health among blacks. J. Racial Ethn. Health Disparit. 2015, 1-8. [CrossRef] [PubMed]

62. Kim, G.; Bryant, A.; Huang, C.; Chiriboga, D.; Ma, G.X. Mental health among Asian American adults: Association with psychiatric. Asian Am. J. Psychol. 2012, 3, 44-52. [CrossRef]

63. Arango-Lasprilla, J.C.; Kreutzer, J.S. Racial and ethnic disparities in functional, psychosocial, and neurobehavioral outcomes after brain injury. J. Head Trauma Rehabil. 2010, 25, 128-136. [CrossRef] [PubMed]

64. Assari, S.; Lankarani, M.M. Stressful Life Events and Risk of Depression 25 Years Later: Race and Gender Differences. Front. Public Health 2016, 4, 49. [CrossRef] [PubMed]

65. Assari, S.; Lankarani, M.M. Association between Stressful Life Events and Depression; Intersection of Race and Gender. J. Racial Ethn. Health Disparit. 2016, 3, 349-356. [CrossRef] [PubMed]

66. Assari, S. Psychiatric disorders differently correlate with physical self-rated health across ethnic groups. J. Pers. Med. 2017, in press.

67. Choi, H.; Fogg, L.; Lee, E.E.; Wu, M.C. Evaluating differential item functioning of the CES-D scale according to caregiver status and cultural context in Korean women. J. Am. Psychiatr. Nurses Assoc. 2009, 15, 240-248. [CrossRef] [PubMed]

68. Kim, M.; Han, H.R.; Phillips, L. Metric equivalence assessment in cross-cultural research: Using an example of the Center for Epidemiological Studies-Depression Scale. J. Nurs. Meas. 2003, 11, 5-18. [CrossRef] [PubMed]

69. Green, J.G.; Gruber, M.J.; Kessler, R.C.; Lin, J.Y.; McLaughlin, K.A.; Sampson, N.A.; Zaslavsky, A.M.; Alegria, M. Diagnostic validity across racial and ethnic groups in the assessment of adolescent DSM-IV disorders. Int. J. Methods Psychiatr. Res. 2012, 21, 311-320. [CrossRef] [PubMed]

70. Assari, S.; Moazen-Zadeh, E. Ethnic Variation in the Cross-sectional Association between Domains of Depressive Symptoms and Clinical Depression. Front. Psychiatry 2016, 7, 53. [CrossRef] [PubMed]

71. Scollon, C.N.; Diener, E. Love, work, and changes in extraversion and neuroticism over time. J. Personal. Soc. Psychol. 2006, 91, 1152-1165. [CrossRef] [PubMed]

72. Assari, S. Unequal Gain of Equal Resources across Racial Groups. Int. J. Health Policy Manag. (IJHPM) 2017, 6, 1-9. [CrossRef]

73. Kan, C.; Kawakami, N.; Umeda, M. Mediating role of psychological resources on the association between childhood socioeconomic status and current health in the community adult population of Japan. Int. J. Behav. Med. 2015, 22, 764-774. [CrossRef] [PubMed]

(C) 2017 by the author. Licensee MDPI, Basel, Switzerland. This article is an open access article distributed under the terms and conditions of the Creative Commons Attribution (CC BY) license (http://creativecommons.org/licenses/by/4.0/). 